\title{
O PRAGMATISMO DE JOHN DEWEY E A AÇÃO PEDAGÓGICA INTELIGENTE
}

Ivan Luís Schwengber ${ }^{(*)}$ Jenerton Arlan Schütz ${ }^{(* *)}$

\section{INTRODUÇÃO}

Podemos considerar que os alunos encontram certo grau de motivação no ambiente escolar contemporâneo, tal relação depende, prioritariamente, do interesse do aluno e da qualidade do ambiente em que este se encontra. Há, entretanto, uma patologia que impossibilita uma relação concreta e saudável nas escolas, remetendo à uma multivariegada gênese, que vai das péssimas condições de infraestrutura de um grande contingente de nossas escolas públicas à precariedade da formação e valorização dos professores que nelas atuam. Além disso, podemos também assegurar que existe na educação escolar hodierna um grave problema com a indisciplina escolar. A dificuldade de respeito dos jovens em relação ao seu mestre e, muitas vezes, inclusive com os seus pares, é um problema formativo, ético e cultural na sociedade contemporânea.

Nesse sentido, vários são os fatores interpessoais que o professor necessita oferecer aos seus alunos a fim de que encontrem um "chão seguro" na escola, entre eles, podemos citar: a autoestima, a direção de metas, o estímulo, a utilização de tecnologias, a ludicidade, a inovação, a adequação às vontades dos alunos etc, tudo para que o aluno se torne interessado pela aula, conteúdo e escola. $\mathrm{O}$ que não significa que ele esteja aprendendo ou internalizando os conhecimentos historicamente constituídos pela humanidade. Ademais, podemos considerar que a indisciplina se faz presente nas escolas e se manifesta dentre as mais variadas formas, desde jogar papeizinhos no colega, conversas que atrapalham o bom andamento da aula, até mesmo a violência e o vandalismo no ambiente escolar.

Se, por um lado, constatamos que há um grave problema de indisciplina em nossas escolas, por outro, vários são os fatores que contribuem para a falta de interesse dos alunos, o que só consolida a afirmação de que temos um sistema formativo que necessita ser (re)pensado. Neste

\footnotetext{
(*) Mestre em Educação (Unochapecó), Especialista em Metodologia de Ensino de Filosofia (Educon) e Sociologia e Gestão Escolar (Uniasselvi), Licenciado em Filosofia (Fafimc). Professor da Rede Estadual de Ensino do Estado de Santa Catarina. E-mail: ivan.s@unochapeco.edu.br.

${ }^{(* *)}$ Doutorando em Educação nas Ciências (Unijuí), Mestre em Educação nas Ciências (Unijuí), Especialista em Metodologia de Ensino de História (Uniasselvi), Licenciado em História e Sociologia (Uniasselvi). Bolsista CAPES. Email: jenerton.xitz@hotmail.com.
} 
caso, necessitamos que os alunos sejam constantemente desafiados, mobilizados, sensibilizados, devem perceber a relação entre o conteúdo e seu contexto diário, as suas necessidades, problemas e interesses, por isso, é imprescindível a criação de um clima de predisposição favorável à aprendizagem. Consideramos que tais movimentos ajudam a criar possibilidades para uma ação pedagógica inteligente.

Nessa direção, o texto aborda a questão da falta de interesse e o mau uso da disciplina como um problema filosófico da educação, parte-se, por isso, de uma reflexão teórica para repensar conceitos e a forma de abordagem da temática. A partir do pragmatismo de John Dewey, objetivase investigar a ação pedagógica inteligente no contexto da educação escolar. Outrossim, faz-se necessário indagar sobre os princípios que podem ser considerados coerentes com a ação pedagógica inteligente. Nesse sentido, a hipótese que aqui asseguramos, considera que uma ação pedagógica inteligente, refere-se ao momento em estamos a educar a vontade do sujeito, fazendo com este seja considerado em seu contexto social e na temporalidade (longa e lenta) em que a educação se insere.

Consideramos que uma ação que não alcança seus resultados esperados não é exitosa: a falta de vontade, ou uma vontade forte para alcançar os objetivos é um problema pedagógico (de instrução) que tem pilares, segundo Dewey, no interesse e na disciplina.

Para tecer os fios da presente temática com as reflexões apresentadas por Dewey, utiliza-se, especialmente, o Capítulo X, intitulado "Interesse e Disciplina" e que está presente no conjunto da obra Democracia e Educação (1916). Nessa direção, iniciamos situando a relevância do pragmatismo educacional, o que perifericamente, contribuiu para denunciar e descontruir o aspecto depreciativo ou negativo do pragmatismo presente nos discursos pedagógicos contemporâneos.

Portanto, o presente manuscrito é uma forma de tratamento da questão da falta de interesse e disciplina à luz das reflexões do pragmatismo de Dewey. Sob a ótica do materialismo-histórico e dialético algumas das questões aqui abordadas parecem perder o sentido, haja vista a mobilização ideológica e política que se faz em torno dos problemas educacionais.

\section{O PRAGMATISMO PEDAGÓGICO DE DEWEY}

A palavra pragmatismo tem um aspecto negativo dentro da tradição pedagógica em virtude da seguinte máxima: “A interação com as coisas pode criar hábitos de adaptação externa. Mas só conduz a uma atividade que tenha significação e propósito consciente quando se utilizam as coisas para a obtenção de algum resultado.” (DEWEY, 1979, p. 36). A coisificação das pessoas e a 
compreensão de forma negativa, utiliza o Outro ao seu bel prazer, chegando a compreensão popular denominada de "segundas intenções". Esta simplificação do problema é somente uma potencialização do aspecto negativo do pragmatismo, que aqui, pretendemos demonstrar ser errônea.

A origem do termo Pragmatismo é filosófica e atribuída a Pierce, da qual Dewey era segmentário de um Pragmatismo Metodológico, em que a experiência justifica as proposições em conexão com a vida (ABBAGNANO, 2003). Na educação brasileira, o pragmatismo insere-se a partir das reflexões de Anísio Teixeira, que não foram bem aceitas pela tradição históricomaterialista.

O pragmatismo de Dewey e sua relação com a educação, faz tecer uma crítica ao modelo tradicional, representado pelo modelo escolástico, onde prevalecia a passividade do aluno e a necessidade de memorização das verdades universais. O pragmatismo de Dewey serve para repensar as ações pedagógicas e criar uma nova teoria educacional. A perspectiva pragmatista adota uma mudança na estrutura antropológica agenciadora, em que o estudante é um ativo participante de sua formação.

O núcleo da teoria pragmatista da ação repousa no conceito de ser humano como organismo agente, cuja a capacidade de produzir e empregar símbolos significativamente permite interagir ativamente consigo mesmo e com o meio físicosocial mais amplo. (DALBOSCO, 2010, p. 54).

A ação pedagógica inteligente está estruturada sob uma forte noção de linguagem, a saber, a relação simbólica entre professores e alunos. Em suma, a ação pedagógica entre sujeitos ativos é realizada através da linguagem.

A segunda característica antropológica deweyana é de romper com o dualismo mente e corpo, tanto no idealismo quanto no realismo. No idealismo, o ensino torna-se contemplativo das verdades essenciais e, por consequência, transcendentais. Toda ação pedagógica tende a adequar nossa alma, as estáticas verdades universais, em que a agitação sensível, as paixões corpóreas são uma deturpação. O resultado disto se reflete na escola, onde ela deve aproximar-se de um monastério, em que sujeito-aprendiz se purificam de suas meninices joviais, na tendência de, com seriedade e certo grau de sofrimento, aceitar os ensinamentos dos mestres.

No realismo, representado pelo behaviorismo ortodoxo, em que predomina um ativismo exacerbado, toda ação pedagógica depende de fatores exteriores e ambientais. Nas escolas isto reflete ora nos recursos tecnológicos utilizados para movimentar a ação pedagógica, em que 
professor deve usar os recursos cibernéticos; ou ainda, em que as aulas usam-se de recursos predominantemente lúdicos, adquirindo aspecto dramatúrgico.

Contudo, consideramos que a educação deve agregar algo, pois, assim como o corpo, a mente também se desenvolve, esta concepção antropológica expressa em Democracia e Educação é o centro da crítica de Dewey sobre o "conceito substancial e estático de mente." (DALBOSCO, 2010, p. 56). Nota-se que há uma influência do behaviorismo que não dualiza mente e corpo, assim, a educação é um fazer que envolve o ser humano como um todo, e resulta na relação social democrática, dito de outro modo, a educação produz resultados para com a democracia.

Uma interpretação deste ideal democrático - salvo suas devidas diferenças - é expressa por Paulo Freire em sua obra Educação como prática da Liberdade (1967) quando afirma que: “A democracia que, antes de ser forma política, é forma de vida, se caracteriza sobretudo por forte dose de transitividade de consciência no comportamento do homem" (FREIRE, 1967, p. 81), conectando a formação do sujeito com o aspecto social democrático.

O homem é um “organismo agente" (DALBOSCO, 2010, p. 58), que influencia e é influenciado pelo ambiente físico e social e, é esta relação simbólica que atribui significado. Estes símbolos são exteriores, mas com significados. Esta simbologia linguística permite agir prospectiva e retrospectivamente e, por consequência, ensinar e aprender. Podemos, desse modo, ressignificar os fatos ocorridos e antever o futuro. $\mathrm{Na}$ educação lidamos simbolicamente com a noção tridimensional do tempo.

A educação somente ocorre ativamente, por isso, trata-se de uma ação pedagógica inteligente, e esta, refere-se aos momentos em que respondemos aos estímulos do ambiente de forma simbólica, não obstante, uma atividade simbólica pode e é um manuseio de símbolos significativos.

Esta atividade do espírito que estabelece relação exterior com o mundo, através da linguagem simbólica, tem constituição no âmbito intersubjetivo. A atividade do espírito humano simbólico tem como ponto de partida o aspecto social, pois, é socialmente que recebemos significados e reagimos a eles simbolicamente, e somente neste ambiente social e físico que exercemos influência sobre outros espíritos.

Uma ação que pretende ter certo efeito é caracterizada como uma ação inteligente e, por isso, esta ação é mediada pelo interesse e disciplina. Tal concepção é tratada no capítulo X da Democracia e Educação, intitulado: Interesse e Disciplina, doravante, este será o objeto de nossas análises doravante. 


\section{A TEORIA DA AÇÃO PEDAGÓGICA INTELIGENTE}

As escolas e os sistemas de ensinos atuais estão constantemente se adaptando para tentar tornar a formação algo mais atrativo para os nossos jovens e crianças. Com isso, as crianças sentemse, inicialmente, muito atraídas pelas escolas e, conforme vão avançando, sentem-se desinteressadas e desmotivadas. Todavia, nosso objetivo aqui não é analisar os fatores psicológicos de desenvolvimento que contribuem para este fato, objetiva-se, entretanto, compreender os princípios que regem e contribuem para uma ação inteligente no contexto educacional.

Consideramos, com efeito, que esta desmotivação tem influência filosófica no problema de separação da mente e corpo, em que há um problema de determinação da vontade. Esta busca de determinação da vontade encontra-se arraigada dentro de um imbricado compromisso ético. Esta ambiguidade é expressa por David Hume no seu livro Tratado da natureza humana (1739-1740) onde considera que: "Uma coisa é conhecer a virtude, e outra conformar a vontade com ela" (HUME, 2000, p. 505), em outras palavras, poderíamos reduzir em saber e querer, o que na tradição ficou entre a razão e as paixões, o conhecimento está ligado ao intelecto, e deve ser purificado com as paixões e os desejos sensíveis.

Uma vontade que, ou seguia as determinações racionais ou deixava-se levar pela corporeidade, uma ambiguidade da vontade, resultante num dualismo dilacerante, que reflete em sérios problemas para os seres humanos. Dito isto, há uma teoria da determinação da vontade na concepção da ação pedagógica de Dewey, ancorada no interesse e na disciplina, “[...] considerações de valor geral para toda a Filosofia da Educação.” (DEWEY, 1916, p. 153, tradução nossa). A educação deve se tornar a nossa ação inteligente enfrentando o problema da instrução (problem of intruction).

A vontade e o querer precisam ser instruídos, educados pelo interesse que é a mola propulsora e pela disciplina que é a sua regradora. O querer fraco (weak will) é muito inconstante “instável como a água.” (DEWEY, 1916, p. 150, tradução nossa). A vontade, por um lado, deve se mover a algo, estar interessada, e por outro, deve manter uma certa retidão, pra que não se jogue do acaso.

Não obstante, para Dewey, a vontade possui dois elementos: "Um tem a ver com a previsão dos resultados, e o outro com que a profundidade que se espera desta previsão dos resultados que tem sobre a pessoa.” (DEWEY, 1916, p. 150, tradução nossa). Neste caso temos o efeito da ação, ou seja, os fins esperados e, por isso, um homem inteligente deve (ao menos deveria) agir e pesar os fins de sua ação. 
Para Dewey (1916), a diferença de um homem com uma vontade fraca ou uma vontade forte é simplesmente intelectual, ou seja, ele deve ser capaz de pensar os possíveis fins de sua ação, mantendo-se perseverante e firme em sua ação. Alguém com uma vontade fraca não dispõe de capacidade intelectual suficientemente desenvolvida para saber o que implica a sua vontade. A vontade implica na realização de uma ação, uma realização, que implica em algumas consequências físicas e sociais, a capacidade de saber pesar estas e manter-se firme é característica de um ser humano que tem uma vontade instruída, consequentemente uma vontade forte (strong volition). Quando não se percebe que a vontade é uma capacidade executora, temos um tipo de vontade intelectual que é incapaz de perseverar na sua realização, é um tipo de querer sem fazer. Esta vontade que carece de inteligência é fraca, pois não se compromete com as consequências. Durante o percurso, o sujeito (fraco) sente algumas dificuldades executivas e se deixa seduzir por atividades imediatamente mais agradáveis. Esta característica da vontade se refere ao sujeito agente que não se compromete com seus resultados.

Disto discorremos que, uma ação inteligente é uma ação realizada por uma pessoa com uma vontade forte, vontade esta instruída por uma capacidade intelectual executiva. A tradicional cisão mente e corpo contribui para uma ação ingênua, desenvolvida intelectualmente, contudo, abstrata e paralisante, que não leva a considerar as consequências físico-sociais que provoca. Ademais, a ação é uma ação inteligente de uma pessoa com vontade forte e, esta vontade precisa considerar o interesse.

Consideramos que o interesse é uma conexão entre a pessoa e o mundo comum. Em que a pessoa se vê como parte integrante do mundo. O interesse move o sujeito para a ação, pesando as consequências futuras - os resultados -, outrossim, despertam no sujeito a possibilidade de que ele possa agir para conseguir o resultado. A simples previsão de algo não assegura a pessoalidade do interesse, pois, podemos prever coisas completamente alheias a nossa atitude, e isto não desperta o interesse, ou a atividade do/no sujeito. A previsão impessoal leva o sujeito a ser passivo, enquanto o interesse conduz a ser um sujeito ativo:

Mas para ser ativo, um ser é parte que participa das consequências em vez de ficar estranho as mesmas, existe ao mesmo tempo uma reação pessoal. A diferença imaginativamente prevista cria uma diferença atual que se exprime pelo cuidado e esforço [...]. Podemos dominar o aspecto de previsão objetiva, intelectual e o aspecto pessoal, emocional e volitivo, mas não há separação entre os fatos constitutivos de tal situação. (DEWEY, 1979, p. 137). 
O sujeito ativo é o sujeito que pessoalmente sente-se motivado para agir, mas esta motivação está ligada à capacidade de imaginar. Imaginação que leva compreender o esforço e o cuidado na execução da ação. Com isso, "o interesse representa a força que faz mover os objetos quer percebidos, quer representados em imaginação em alguma experiência provida de um objetivo" (DEWEY, 1979, p. 142), significa dizer que a vontade de ação implica na motricidade tanto dos objetos quanto dos objetivos, pondo o sujeito em movimento.

Nesse sentido, tanto a previsão intelectual como aquilo que vamos sentir pode ser representado separadamente, mas nunca possui tamanha imbricação e intensidade como a situação que a ação envolve. Fazendo com que uma sensação se sinta parte da situação.

Esta inseparabilidade entre o aspecto subjetivo (querer e desejo) e o aspecto objetivo são determinantes para o interesse, uma vez que o interesse e a preocupação, significam que o eu (self) e o mundo estão engajados um como outro no desenvolvimento de ação. (DEWEY, 1916). Esta é a conexão profunda que marca o interesse, o próprio Dewey frisa que a palavra interesse significa “entre-esse" (between), isto é, entre coisas distantes.

A vontade forte precisa, necessariamente, estar interessada, sentir-se conectada com o mundo para sua realização. Porém, consideramos que o interesse não é condição suficiente para determinar uma vontade forte e, consequentemente, uma ação inteligente, pois a capacidade intelectual somente se realiza pelo exercício ativo e contínuo: a disciplina. Como já consideramos, muitas coisas ocorrem independente da participação do sujeito - o que leva a uma situação passiva; outras atividades vitais dependem da condição ambiental - que se extinguem naturalmente na situação, fazendo com que o sujeito se deixe levar pela conexão espontânea e/ou pelas necessidades imediatas.

A determinação da vontade para uma ação inteligente precisa de certo tempo para ser executada, superando, desse modo, os obstáculos e persistindo na execução da ação. Uma vontade que tem capacidade de ação, necessariamente, precisa da disciplina para a efetivação. Se não tem disciplina a vontade não se realizará, e consequentemente sua ação não será inteligente - pois o sujeito começará interessado e no primeiro obstáculo a tendência é desanimar.

Disciplina significa energia à nossa disposição; o domínio dos recursos possíveis para levar avante a atividade empreendida. Saber o que se deve fazer e fazê-lo prontamente e com a utilização dos meios requeridos, significa ser disciplinado, quer se trate de um exercício, quer seja de um espírito. A disciplina é positiva. (DEWEY, 1979, p. 141).

Nesta passagem, Dewey frisa que saber utilizar os meios possíveis para executar uma atividade exige disciplina. Estes meios possíveis, tanto físicos como mentais, implicam em um não 
sofrimento voluntário, mas sempre numa conexão entre mente e corpo, por isso, a disciplina para ser inteligente deve ser e ter direcionamento da vontade, diferentemente de um sofrimento deliberado.

A disciplina estabiliza a vontade num resultado a longo prazo (tal como a educação), tornando a vontade forte. E para execução de resultados maiores esperados, obviamente passamos por momentos em que nossos desejos e paixões são direcionados para um fim maior, o que parece ser um sofrimento - e é justamente assim que muitos alunos consideram o processo de ensino e aprendizagem. O sofrimento se não for inteligente, será desnecessário, e decididamente não é uma ação inteligente.

Por outro lado, o aspecto da temporalidade é uma característica que passa quase despercebida, mas que tem uma relevância significativa para disciplinar a vontade. Manter-se temporalmente comprometido com os fins exige muita disciplina, sempre no aspecto da atividade, o que parece ser potencializado pela experiência ou conhecimento de vida, no sentido de se ter pouco a pouco disciplinado a vontade para os fins (re)queridos.

Ademais, necessitamos compreender como uma vontade forte pode ser educada, considerando o interesse e a disciplina.Com isso, fica em aberto o problema da instrução como conexão da Filosofia da Educação de Dewey.

\section{CONSIDERAÇÕES E POSSIBILIDADES DA TEORIA DA AÇÃO PEDAGÓGICA INTELIGENTE}

Reconhecemos que uma ação inteligente é uma ação que tem uma vontade forte, uma vontade que é interessada e disciplinada. Uma ação inteligente é uma ação que se faz e se sente parte do mundo comum. Todavia, quais são os reflexos de uma ação inteligente para com a formação do sujeito?

Para uma ação pedagógica ser inteligente, nomeadamente, ela deve ser interessante e disciplinadora, em que os sujeitos envolvidos sintam-se parte do processo formativo, em suma, dele sejam participantes ativos. Contudo, como podemos fazer com que os alunos realmente sejam participantes?

Antes de responder a pergunta, consideramos ser proveitoso demonstrar um exemplo sugestivo de Dewey entre o espectador e o participante. Temos situações de espectadores e participantes na sala de aula. O espectador assiste a aula numa atitude passiva, logo, não se envolve, é como se o mundo e a situação ocorressem alheios a ele, já o aluno participante está envolvido com 
o processo, sentindo-se corresponsável. O último exemplo soa quase como uma utopia de sala de aula frente às multivariegadas gêneses da educação contemporânea.

Para despertar a participação do aluno é necessário considerar seu interesse. Uma vez que

[...] nos casos concretos, o valor de se reconhecer a função dinâmica do interesse em um desenvolvimento educativo é que leva a considerar individualmente as crianças em suas aptidões, necessidade e preferências especiais. Quem reconhecer a importância do interesse não presumirá que todos os espíritos funcionam de mesmo modo pela razão de acontecer-lhes terem o mesmo professor e mesmo compêndio. (DEWEY, 1979, p. 142).

Considerar o interesse de cada aluno é uma forma de torná-los partes do processo pedagógico, fazendo com que estes se sintam comprometidos com a aula, isto não significa que se deva atender aos desejos particulares de cada um, como também não considerar todos iguais e naturalmente interessados pela disciplina. Desta forma, o professor deve motivar os alunos a tomarem-se parte da aula, sentindo-se, desse modo, envolvidos e corresponsáveis. Importa ressaltar que a autoridade docente deriva do reconhecimento de uma assimetria geracional entre aqueles que estão há mais tempo no mundo e aqueles que nele acabam de adentrar. O que está em jogo não é o poder ou o domínio sobre os demais, mas a garantia da durabilidade e continuidade de um mundo comum.

Na convergência com o pensamento de Dewey, Herbart (2003) considera que o interesse é entendido como a ação e aquilo que a ela conduz imediatamente (o desejo). Assim, interesse e desejo representam a totalidade de uma emoção humana manifesta, e a educação orientada por esse interesse ocupa-se de fazer com que cada criança consiga, por si mesma, distinguir entre vários anseios (desejos) pelos objetos e decidir quais deles merecem (ação) preferência, estímulo e expressão.

Para esclarecer as relações e diferenças entre vontade, gosto, desejo e interesse, Herbart (2003, p. 69) reitera que:

O interesse, que juntamente com o desejo, a vontade e o gosto se opõe à indiferença, distingue-se dos três pelo facto de não poder dispor do seu objeto, mas de estar dependente dele. É certo que somos interiormente ativos ao manifestarmos interesse, mas exteriormente ociosos até que o interesse se transforme em desejo e vontade. [...] O objeto do interesse nunca se pode identificar com o que é desejado, porque o desejo (ao querer apropriar-se de algo) aspira a algo de futuro que ainda não possui. O interesse, pelo contrário, desenvolve-se com a observação e prende-se ao presente observado. O interesse só transcende a simples percepção, pelo facto de nele a coisa 
observada conquistar de preferência o espírito e se impor mediante certa causalidade entre as outras representações.

Nessa direção, a atividade pedagógica, a matéria, o currículo, as aptidões adquiridas são de forma geral estranhas, e não despertam natural interesse, pois, simplesmente "[...] supõe-se serem estranhas à atividade normal dos discípulos.” (DEWEY, 1979, p. 138). Trazer para a proximidade do mundo da vida do estudante, é o que Freire, de alguma forma, denominara de "universo vocabular", em que parte do princípio de que todos participam do mundo da cultura, uma identificação como parte do processo, no e com o mundo, em suas dimensões da cultura e da natureza.

O papel ativo do homem em sua e com sua realidade. O sentido de mediação que tem a natureza para as relações e comunicação dos homens. A cultura como o acrescentamento que o homem faz ao mundo que não fez. A cultura como o resultado de seu trabalho. Do seu esforço criador e recriador. O sentido transcendental de suas relações. A dimensão humanista da cultura. (FREIRE, 1967, p. 108).

Desta forma, o educando sente-se produtor da cultura, participante do mundo comum. Contudo, a diferença é que Freire pensava enquanto participante da cultura, ao passo que Dewey vai à singularidade de cada indivíduo. A proposta de Dewey é clara, pois busca usar meios necessários para atrair os alunos para a matéria e/ou os conteúdos, estes meios necessários são objetos ou modos de conectar a matéria e/ou o conteúdo ao interesse do aluno. Segundo o autor, "é descobrir objetos e modos de agir que se relacionem com as aptidões existentes. Fazer este material acionar a atividade para exercer-se com coerência e continuidade - eis o interesse do mesmo." (DEWEY, 1979, p. 139). Logo, uma ação pedagógica inteligente deve levar em consideração o interesse dos alunos, contudo, isso não exime o professor de sua autoridade ${ }^{1}$ pedagógica.

Despertado este interesse, entre o sujeito e a matéria e/ou o conteúdo, a execução temporal passa a envolver a disciplina. A disciplina, como vimos, é o exercício executivo da vontade com o fim a que se propôs. A disciplina envolve certos exercícios, objetos e situações que se usam para alcançar determinados fins. Em sala de aula, muitas atividades que se fazem, são exercícios disciplinadores para alcançar os fins, mas só farão sentido para o aluno quando este se sentir parte do processo, caso contrário a atividade permanece enfadonha e, em certo sentido, punitiva. Uma

\footnotetext{
${ }^{1}$ Arendt distingue autoridade de certas formas de força e/ou violência. Mesmo que em ambos os casos se possa falar de uma relação hierárquica e de obediência, aquele que obedece ao mais forte o faz por medo ou por ser forçado fisicamente a obedecer, enquanto aquele que obedece à autoridade o faz por consentimento. (ARENDT, 2013). Nesse sentido, o professor pode constituir uma autoridade frente ao aluno, "[...] se ambos reconhecem a legitimidade do mundo comum e a necessidade de sua continuidade.” (ALMEIDA, 2011, p. 39).
} 
ação pedagógica inteligente é, portanto, uma ação que necessariamente disciplina o sujeito para a ação, característica de quem tem uma vontade forte.

Toda vontade busca a realização em uma ação, rebatendo o dualismo corpo e mente, não há uma teoria e uma prática distinta, todo conhecimento leva à ação, que é considerada como um "ato de natureza executiva." (DEWEY, 1979, p. 142). Paulo Freire também pleiteou em termos a necessidade do conhecimento levar à ação: "Acontece, porém, que a toda compreensão de algo corresponde, cedo ou tarde, uma ação. Captado um desafio, compreendido, admitidas as hipóteses de resposta, o homem age. A natureza da ação corresponde à natureza da compreensão.” (FREIRE, 1967, p. 105-106).

A vontade forte, potencializada pelo interesse e disciplina, torna a execução inteligente, uma espécie de acrescentamento ao sujeito:

A inteligência não é uma coisa particular que alguém possua, mas uma pessoa é mais ou menos inteligente, na proporção que as atividades de que é participante tenham mais ou menos as qualidades mencionadas. Nem são as atividades em que uma pessoa se empenha, inteligentemente ou não, exclusiva propriedade sua; são alguma coisa em que a referida pessoa se empenha e toma parte. (DEWEY, 1979, p. 144).

Esta noção de inteligência tem uma força ativa poderosa, pois a inteligência não depende do estado essencial do sujeito, ou seja, de seus atributos pessoais, mas tem uma capacidade de agir em relação a outra pessoa para a realização de seu propósito, nisto consiste a dimensão do empenho ou engajamento em participar. Alguém é inteligente na medida em que age e participa - toma parte. Em uma sala de aula não existem alunos mais ou menos inteligentes, existem os que participam, tomam parte e agem de acordo com as ações e situações propostas pedagogicamente.

Nesse sentido, existe um fator social muito importante e que estamos passando por demasiada rapidez, a saber, a interação com outras pessoas. Não há execução da vontade sozinho, não possuímos a autossuficiência contemplativa, mas somos seres cooperativos, o que significa que necessitamos interagir com outros agentes. Numa situação pedagógica, por exemplo, o professor consciente de sua atividade profissional, tem de estabelecer a cooperação com a escola e os diferentes sujeitos envolvidos no processo, o que, de certo modo, apresenta algumas implicações. Uma ação pedagógica inteligente envolve o interesse dos participantes, envolve a disciplina, com uma vontade forte, que partilha interações e troca de energias entre todos os agentes envolvidos.

Portanto, a inteligência da ação pedagógica está no âmbito interacional e ativo, na capacidade de estabelecer cooperações, agindo com sinergia para com os fins propostos, do qual todos participam, tomando o processo como parte comum. Na sala de aula, a assimilação e a 
realização das atividades pedagógicas deve envolver a participação dos alunos com interesse e disciplina. Um professor com uma ação pedagógica inteligente necessita estabelecer esta cooperação formativa.

\section{CONSIDERAÇÕES FINAIS}

O objetivo em estabelecer uma ação pedagógica inteligente transitando pelo pragmatismo de Dewey nos trouxe à baila inúmeras reflexões que nos podem ajudar nas relações pedagógicas que carecem de interesse e participação por parte dos alunos. Munidos da investigação filosófica, conseguimos estabelecer alguns pontos que convergem para a melhora do interesse, assumindo, grosso modo, a máxima de ação pedagógica inteligente.

O sobrevoo inicial, proporcionou pertinentes reflexões sobre o pragmatismo e a educação escolar, com a máxima maquiavélica de que os fins justificam os meios, para, desse modo, estabelecer a visão um tanto pejorativa do pragmatismo na situação educacional brasileira, possibilitando a compreensão de sua envergadura.

Gostaríamos de destacar o estabelecimento da proposta de Dewey no cenário democrático, tal perspectiva não foi discutida diretamente no texto, entretanto, afirmar que toda a ação pedagógica está inserida num contexto social, consequentemente num ideal de democracia, pois, partilhando do pensamento deweyano, a instituição escolar deve promover a vida e o ambiente social plural e democrática. A escola é, nessa perspectiva, um dos lugares que dispomos para o exercício da vida democrática; não é nem uma preparação nem uma antecipação, mas um lugar natural de experimentação do convívio democrático, ideal este também compartilhado por Paulo Freire.

A noção filosófica da determinação da vontade, a partir do interesse e da disciplina, configuram o estabelecimento de uma vontade forte. Para não sermos joguetes ao acaso, precisamos educar a vontade na direção que possa alcançar os resultados e também se comprometer com estes. Assim, uma ação pedagógica inteligente deve ser ao mesmo tempo exitosa e, por consequência, participativa.

Não há uma relação pedagógica inteligente que não envolva a cooperação dos sujeitos envolvidos e, por consequência, o comprometimento com os meios e os fins propostos. Neste ponto de vista, o enganche deweyano, considera que o professor necessita estar atento aos interesses dos alunos, propondo meios e situações que conectem a matéria com os seus interesses, logo, 
necessita de disciplina. A disciplina é positiva porque trabalha com os meios a longo prazo para alcançar os resultados desejados.

Deixamos em aberto algumas questões ainda possíveis de serem discutidas e sugestivas na perspectiva de Dewey, além disso, fica aqui o registro para que as preocupações assumidas neste estudo, e as inquietações e a ânsia por novos horizontes provocativos, possam levar a outros caminhos, novas pesquisas, novos problemas e possibilidades.

\section{REFERÊNCIAS}

ABBAGNANO, N. Dicionário de Filosofia. Tradução de Alfredo Bosi. 4. ed. São Paulo: Martins Fontes, 2003.

ALMEIDA, Vanessa S. de. Educação em Hannah Arendt: entre o mundo deserto e o amor. São Paulo: Cortez, 2011. ARENDT, Hannah. Entre o passado e o futuro. Tradução de Mauro W. Barbosa. 7. ed. São Paulo: Perspectiva, 2013.

DAlbosCO, C. A. Pragmatismo, teoria crítica e educação: a ação pedagogica como mediação de significados. Campinas: Autores Associados, 2010.

DEWEY, J. Democracy and Education: An introdution to the philosophy of education. New York: The Macmilian Company, 1916.

Democracia e Educação: uma introdução à filosofia da educação. Tradução de Godofredo Rangel e Anísio Teixeira. São Paulo: Companhia Editora Nacional, v. 21, 1979.

FREIRE, P. Educação como Prática da Liberdade. Rio de Janeiro: Paz e Terra, 1967.

HERBART, F. Pedagogia Geral. Lisboa: Fundação Calouste Gulberkian, Grafica de Coimbra, 2003.

HUME, D. Tratado da Natureza Humana. Tradução de Débora Danawski. São Pualo: Unesp, 2000. 


\section{RESUMO}

Este texto aborda a questão da falta de interesse e o mau uso da disciplina como um problema filosófico da educação, parte-se de uma reflexão teórica para repensar os conceitos e a forma de abordagem da temática. A partir do pragmatismo de John Dewey, o presente escrito objetiva investigar a ação pedagógica inteligente no contexto da educação escolar. Outrossim, faz-se necessário indagar sobre os princípios que podem ser considerados coerentes com a ação pedagógica inteligente. Nesse sentido, a hipótese que aqui asseguramos, considera que uma ação pedagógica inteligente, refere-se ao momento em estamos a educar a vontade do sujeito, fazendo com este seja considerado em seu contexto social e na temporalidade (longa) em que a educação se insere.

Palavras-chave: Disciplina. Interesse. Vontade.

\section{(DIS)INTEREST, (IN)DISCIPLINE AND INTELLIGENT PEDAGOGICAL ACTION: REFLECTIONS IN THE LIGHT OF JOHN DEWEY'S PRAGMATISM}

\section{ABSTRACT}

This text approaches the question of the lack of interest and the misuse of the discipline as a philosophical problem of the education, part of a theoretical reflection to rethink the concepts and the approach form thematic. From the pragmatism of John Dewey, the present paper aims to investigate intelligent pedagogical action in the context of school education. Also, it is necessary to inquire about the principles that can be considered coherent with the intelligent pedagogical action. In this sense, the hypothesis that we assert here, considers that an intelligent pedagogical action, refers to the moment in which we are educating the subject's will, making it be considered in its social context and in the (long) temporality in which education inserts.

Keywords: Discipline. Interest. Will.

\section{(DES)INTERÉS, (IN)DISCIPLINA Y LA ACCIÓN PEDAGÓGICA INTELIGENTE: REFLEXIONES A LA LUZ DEL PRAGMATISMO DE JOHN DEWEY}

\section{RESUMEN}

Este texto aborda la cuestión de la falta de interés y el mal uso de la disciplina como un problema filosófico de la educación, se parte de una reflexión teórica para repensar los conceptos y la forma de abordaje de la temática. A partir del pragmatismo de John Dewey, el presente escrito objetiva investigar la acción pedagógica inteligente en el contexto de la educación escolar. Además, se hace necesario indagar sobre los principios que pueden ser considerados coherentes con la acción pedagógica inteligente. En este sentido, la hipótesis que aquí aseguramos, considera que una acción pedagógica inteligente, se refiere al momento en que estamos educando la voluntad del sujeto, haciendo con éste ser considerado en su contexto social y en la temporalidad en que la educación se ha ido inserciones.

Palabras-claves: Disciplina. Interés. Voluntad. 